\title{
Intracardiac cardiovascular magnetic resonance velocity mapping: comparison of k-t BLAST and SENSE accelerated 4D acquisitions with 2D-flow at I.5 T and $3 \mathrm{~T}$ Carl Crussell*1, Marcus Carlsson ${ }^{1}$, Johannes Toger ${ }^{1}$, Karin Markenroth- Bloch $^{2}$, Hakan Arheden ${ }^{1}$ and Einar Heiberg ${ }^{1}$
}

Address: ${ }^{1}$ Dep of Clinical Physiology, Lund, Sweden and 2 Philips Medical Systems, Lund, Sweden

* Corresponding author

from 13th Annual SCMR Scientific Sessions

Phoenix, AZ, USA. 2I-24 January 2010

Published: 21 January 2010

Journal of Cardiovascular Magnetic Resonance 20 I0, I2(SuppI I):P8I doi:I0.I I86/I532-429X-I2-SI-P8I

This abstract is available from: http://jcmr-online.com/content/I2/SI/P8I

(c) 2010 Crussell et al; licensee BioMed Central Ltd.

\section{Introduction}

Three-dimensional time-resolved (4D) cardiac flow can be visualized and quantified with velocity encoded phase contrast (PC) MRI, but requires a long scanning time. ktBLAST is an efficient technique to reduce scan time, but has not been validated for in vivo 4D-flow applications.

\section{Purpose}

To quantitatively compare flow using k-t BLAST and SENSE 4D-acquisitions with standard 2D-flow at $1.5 \mathrm{~T}$ and $3 \mathrm{~T}$.

\section{Methods}

Cardiac 4D-flow with k-tBLAST and SENSE and nonaccelerated 2D-flow measurements of the aorta and pulmonary trunk were obtained from 7 healthy volunteers (36 \pm 15 years, 5 males) in a $1.5 \mathrm{~T}$ and $3 \mathrm{~T}$ Philips MRI Scanner. Typical 4D-flow parameters for k-t BLAST were: speedup factor 5, 15 time phases, TE/TR/flip: $3.7 / 7.6 \mathrm{~ms} /$ $8^{\circ}$, and for SENSE: parallel imaging factor 2, 40 time phases, TE/TR/flip: $3.7 / 6.3 \mathrm{~ms} / 8^{\circ}$. The voxel size was $3 \times$ $3 \times 3 \mathrm{~mm}^{3}$. 2D-flow was acquired with a PC-FFE sequence with TE/TR/flip: $5.3 / 8.6 \mathrm{~ms} / 15^{\circ}$. 2D-flow was acquired with 35 time phases and voxel size $1.2 \times 1.2 \times 6 \mathrm{~mm}^{3}$. The different sequences for each volunteer were acquired in a random order during a single session. From the 4D datasets, 2D-images perpendicular to the aorta and pulmonary artery were reconstructed using in-house developed software. Flow was measured by outlining the aorta and pulmonary trunk in the velocity encoded 2D-images and these contours were transferred to the reconstructed $4 \mathrm{D}$ images. Stroke volumes (SV) and flow were compared using Wilcoxon's test, linear regression and Bland-Altman analysis.

\section{Results}

2D-flow measurements of the aorta and pulmonary artery showed a strong correlation $\left(\mathrm{r}^{2}=0.94\right)$ and low bias $(2.8$ $\pm 6.1 \%$ ). 4D-flow scan time was reduced using k-tBLAST from $>45 \mathrm{~min}$ to $<10 \mathrm{~min}$. One k-tBLAST $4 \mathrm{D}$ data set was excluded from the $3 \mathrm{~T}$ because of suboptimal image quality. Flow from 4D-SENSE showed similar flow curves compared to 2D-flow (Figure 1) but peak flow was lower on both $1.5 \mathrm{~T}$ and $3 \mathrm{~T}(\mathrm{p}<0.05)$. Peak flow on $4 \mathrm{D} \mathrm{k}-\mathrm{t}$ BLAST was lower than 2D and 4D SENSE flow ( $<<0.05)$.

Table I: Comparison of 4D vs. 2D. Peak flow with 2D at I.5 T: $43 \mathrm{I} \pm 93$ and $3 \mathrm{~T}: 445 \pm 101 \mathrm{ml} / \mathrm{s}$

\begin{tabular}{llll}
\hline Sequence & $\mathbf{r}^{2}$ & $\mathbf{S V}$, bias \pm SD & Peak flow $\mathbf{~ m l} / \mathbf{s}$ \\
\hline I.5 T SENSE = 2 & 0.84 & $-6.2 \pm 16.5 \%$ & $387 \pm 100$ \\
\hline 3 T SENSE = 2 & 0.90 & $-2.5 \pm 8.4 \%$ & $415 \pm 91$ \\
\hline I.5 T k-t BLAST = 5 & 0.65 & $-19.8 \pm 15.6 \%$ & $325 \pm 75$ \\
\hline 3 T k-t BLAST = 5 & 0.63 & $-4.7 \pm 12.3 \%$ & $376 \pm 60$ \\
\hline
\end{tabular}



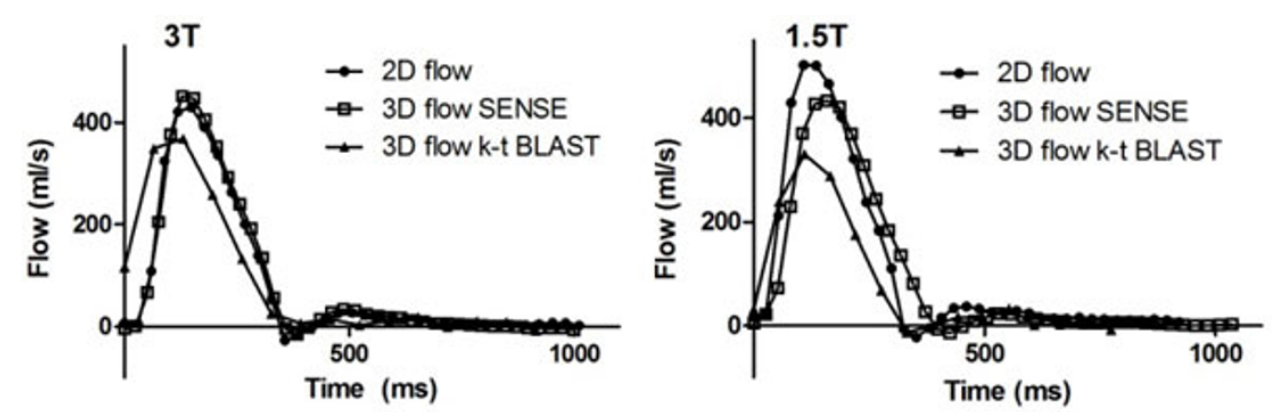

Figure I

The comparison of SV measurements on the 2D- and 4Dflow sequences from both scanners is shown in Table 1. The measurements of SV on 4D-SENSE was not significantly different from $2 \mathrm{D}$ on either scanner $(\mathrm{p}=0.33$ on $1.5 \mathrm{~T}$ and $\mathrm{p}=0.36$ on $3 \mathrm{~T}$ ). SV quantified on 4D k-tBLAST was lower compared to $2 \mathrm{D}$ on $1.5 \mathrm{~T}$ scanners $(\mathrm{p}<0.001)$ but not on $3 \mathrm{~T}(\mathrm{p}=0.47)$.

\section{Conclusion}

Quantitative analysis of flow from 4D-PC-MRI is accurate and reproducible with SENSE. Speed up with k-tBLAST yields lower stroke volumes, peak flows and a weaker correlation compared with $2 \mathrm{D}$-acquisitions.

Publish with Bio Med Central and every scientist can read your work free of charge

"BioMed Central will be the most significant development for disseminating the results of biomedical research in our lifetime. "

Sir Paul Nurse, Cancer Research UK

Your research papers will be:

- available free of charge to the entire biomedical community

- peer reviewed and published immediately upon acceptance

- cited in PubMed and archived on PubMed Central

- yours - you keep the copyright

Submit your manuscript here:

http://www.biomedcentral.com/info/publishing_adv.asp 